\title{
Concepções de educação ambiental e suas abordagens políticas: análise de trabalhos dos Encontros de Pesquisa em Educação Ambiental (I, II e III EPEAs)
}

\author{
Viviane da Silva Junta ${ }^{1}$ \\ Luiz Carlos Santana ${ }^{2}$
}

Resumo: Este artigo analisa os trabalhos apresentados nos I, II e III Encontros de Pesquisa em Educação Ambiental (EPEAs). Tem como corpus documental 61 trabalhos, definidos através de uma amostragem aleatória estratificada a partir das edições dos eventos. Seus objetivos são: a investigação do entendimento dado à dimensão política da educação ambiental, a caracterização das concepções de educação ambiental e a identificação das abordagens políticas dessas concepções. Trata-se de uma análise documental de abordagem qualitativa. A análise foi realizada através das categorias: concepção emancipatória de educação, concepção transformadora da relação sociedade-natureza (que configuram uma concepção transformadora de EA), concepção conservadora de educação e concepção conservadora da relação sociedade-natureza (que definem uma concepção conservadora de EA). Sessenta e quatro por cento dos trabalhos foram compreendidos como concepção transformadora e os $36 \%$ restantes foram considerados portadores de uma concepção conservadora. Dos 61 trabalhos, 18 relacionam educação ambiental com a dimensão política.

Palavras-chave: Educação ambiental transformadora. Dimensão política. Encontros de Pesquisa em Educação Ambiental (EPEAs).

Abstract: This article analyses the works presented in the I, II and III Environmental Education Research Meetings (EERMs). It has a documentary corpus of 61 works, defined through a random sampling stratified from the publications of the events. Its objectives are: the investigation of the understanding of the political dimension of environmental education, the characterization of the environmental education conceptions present in these works, and the identification of the political approaches of these EE conceptions. This inquiry is characterized as a qualitative documentary analysis. The analysis was undertaken through the following categories: emancipatory conception of education, transforming conception of the society-nature relationship (both indicating a transforming conception of EE), conservative conception of education,

1 Educadora da Prefeitura Municipal de Monte Mor - SP vivissd@yahoo.com.br

2 Professor da Unesp - Campus de Rio Claro luizcs@rc.unesp.br 
and conservative conception of the society-nature relationship (both indicating a conservative conception of EE). Most of the EERM works $(64 \%)$ were understood as belonging to the universe of emancipatory and transformative approaches. Among the analysed works, 18 provide some sort of connection between environmental education and political dimension.

Keywords: Transforming environmental education. Political dimension. Environmental Education Research Meetings.

\section{Introdução}

Ao se abordar a crise ambiental, é pertinente realçar o pioneirismo das ciências biológicas na percepção da degradação ambiental. Layrargues (2003a) reconhece o mérito dessas ciências, mas define como possível consequência desse pioneirismo uma perspectiva biologizante (naturalista) da crise ambiental, que reduz a compreensão sobre a mesma deslocando sua resolução do seio da sociedade para a natureza.

Uma perspectiva naturalista compreende a espécie humana de forma genérica como vítima e também responsável pela degradação ambiental, estabelecendo uma dicotomia homem-natureza sem compreensão das mediações presentes nessa relação. Tal abordagem obscurece dois fatos: a forma de viver em sociedade provocou a crise ambiental (FOLADORI, 2000; LAYRARGUES, 2003a) e os conflitos sociais, políticos, econômicos e culturais têm relação direta com a questão ambiental. Não há explicitação do conflito capital-trabalho, das desigualdades sociais, tampouco da questão do poder na sociedade ou de outras questões. A partir dessa referência, a problemática ambiental é compreendida como algo externo à dinâmica social e política, e a natureza é vista como variável externa a ser manejada e gerida (ZHOURI; LASCHEFSKI; PEREIRA, 2005), excluindo uma perspectiva dialética. A questão ambiental aparece como um problema da natureza que deve ser solucionado por meio do conhecimento ecológico, do desenvolvimento técnico-científico e da mudança comportamental dos indivíduos na sua relação com a natureza.

A abordagem naturalista estabelece um equívoco que retira a problemática do universo social, dissimulando seu caráter essencialmente político (BORNHEIM, 1985). Entender esse caráter político é entender que a questão ambiental é uma problemática que remete ao coletivo e à forma de se viver construída historicamente e que também as possíveis soluções envolvem a coletividade, o que pode representar conflitos e rupturas, principalmente em um contexto desigual e hierarquizado como o capitalista.

Ao se abordar a questão ambiental, é importante destacar, no entanto, que ela possui uma especificidade que a caracteriza: ela não se refere a um corpo social determinado, logo, diferencia-se de questões como o movimento operário, o movimento feminista e outros. Devido à sua dimensão antrópica 
(antropogênica) e planetária (LAYRARGUES, 2003a ; SOFFIATI, 2002), há na questão ambiental uma referência a "toda a humanidade", o que pode resultar, por um lado, no falso entendimento de que todos estão consensualmente engajados na resolução dos problemas ambientais e, por outro lado, na incorporação do ideário ambiental por diversos grupos sociais, criando-se múltiplos ambientalismos, ou seja, diversas acepções sobre o que seria a crise ambiental e quais seriam os caminhos para sua solução ou minimização.

A fé num "aparente consenso" se dá com base na premissa de que todos são a favor do estabelecimento de uma relação "saudável" entre homem e natureza, ignorando, porém, que diferentes são as perspectivas de como estabelecer essa relação e que a crise ambiental envolve importantes conflitos (LIMA, 2005).

Vários autores (FOLADORI, 2000; LAYRARGUES, 2003a; LIMA, 2005, entre outros) analisam as tendências ambientalistas, entre as quais podemos elencar: ecossocialismo, ecocapitalismo, ecoanarquismo, ecologia profunda (deep ecology), ecologia superficial, conservacionismo, preservacionismo. Estas podem ser diferenciadas segundo dicotomias de perspectiva: biocêntricas (ecocêntricas) ou antropocêntricas, materialistas ou espiritualistas, conservadoras ou transformadoras, entre outras (LAYRARGUES, 2003a). É necessário assinalar que essas distinções não se dão de forma binária, possuindo entrelaçamentos.

Apesar dos esforços de distinguir o aparente bloco coeso do campo ambientalista, ainda é forte o "aparente consenso" que torna os diferentes discursos não evidentes, o que resulta na apresentação do discurso ambientalista como um discurso único.

Paralelamente ao movimento ambientalista, a educação ambiental reflete a sua variedade de tendências e o "aparente consenso". Muitas são as "educações ambientais" e diversas classificações vêm se formando desde a década de 1980 (LAYRARGUES, 2003b) em torno de determinadas diferenciações. Têm-se classificações a partir do entendimento de meio ambiente, da perspectiva ética, do local onde tal educação ocorre, entre outros critérios.

Tais diferenciações surgiram de uma dupla necessidade: de um lado, tentar tornar menos monolítico o aparente bloco coeso que a EA representa; de outro, concretizar uma educação ambiental que represente maiores possibilidades de resolução da crise ambiental, uma EA transformadora do atual contexto socioambiental.

A educação ambiental é entendida aqui no sentido definido por Brügger (1994): trata-se de uma prática que surge a partir do reconhecimento de que "a educação tradicional não tem sido ambiental", o "“ambiental' deveria ser parte intrínseca da educação como um todo e não modalidade ou uma de suas dimensões" (BRÜGGER, 1994, p. 78).

Destaca-se aqui que a educação ambiental compreendida como processo educativo é uma prática social eminentemente política. E, enquanto tal, é um elemento de significativa importância no processo de humanização. A consciência do homem de seu inacabamento compreende a educabilidade, remetendo a educação à formação humana, o que imprime no processo educativo um sentido ético-político. Como "intervenção no mundo", a educação 
não pode ser neutra, ao contrário, é exigente de opções e de tomada de posições (FREIRE, 2001), o que a situa na reprodução da realidade social ou na transformação desta. Assim, a educação, com base em determinada concepção de homem, de mundo, de processo educativo, de educação ambiental e de crise ambiental, determina a formação do sujeito.

Percebe-se, então, que a dimensão política da educação refere-se justamente à relação com o contexto social no qual os sujeitos estão invariavelmente inseridos. $\mathrm{Na}$ educação ambiental não poderia deixar de ser diferente. A questão ambiental é uma questão política. Ela diz respeito à sociedade e a seus conflitos, de modo que cabe saber como os educadores ambientais vão se posicionar frente a isso.

O conhecimento e o processo educativo são construções históricas não neutras que podem atender a diferentes fins na sociedade. $\mathrm{O}$ caráter político da educação se refere ao reconhecimento da forma como a sociedade se organiza econômica, social e culturalmente e se relaciona com a natureza e da subsequente tomada de posição diante dessa organização e relação.

No sentido aqui trabalhado, a dimensão política da educação não se restringe apenas aos momentos em que a cidadania, a participação, a mobilização ou um ideal transformador é declarado e assumido. Na ausência desses conceitos ou ideais há também uma relação da educação com o universo da política, com a forma que nossa sociedade se organiza: mesmo passando ao largo dessas referências, a educação produz sujeitos sociais a partir de opções assumidas, o que nem sempre está claro para o educador.

A educação como prática social está exposta às relações de poder da sociedade, subordinando-se "a interesses engendrados na dinâmica de relações entre grupos e classes sociais" (LIBÂNEO, 1998, p. 71). Desse modo, a tendência é que haja continuidade nos interesses dominantes quando essa educação não se posiciona de forma crítica perante a realidade e decide se irá conservá-la ou transformá-la.

É imprescindível que haja questionamentos sobre quais concepções de mundo, de homem e mesmo de educação carregamos. O que estamos compreendendo por crise ambiental? Quais são seus determinantes e possíveis caminhos de solução? De qual educação estamos falando? Estas, entre outras, são perguntas que devem ser feitas para que se estabeleçam teorias e práticas mais conscientes e consequentes.

A partir da explicitação de que concepções e práticas de educação ambiental estão necessariamente relacionadas à transformação ou à conservação da realidade socioambiental, visto sua inerente dimensão política, e da existência de um "aparente consenso" nesse campo, a problemática desta pesquisa surge da necessidade de debates a respeito do que diferentes concepções de educação ambiental significam na ótica de sua dimensão política.

Esta pesquisa analisa os trabalhos apresentados nos Encontros de Pesquisa em Educação Ambiental (EPEAs) procurando identificar as concepções de educação ambiental desses trabalhos e suas abordagens políticas. 
A escolha do EPEA se deu em decorrência de sua relevância enquanto evento científico na área, bem como da representatividade que o caracteriza. $O$ EPEA recebe trabalhos de pesquisa e ensaios teóricos sobre a temática ambiental realizados em várias instituições de pesquisa e abrangendo temas variados e diferentes procedimentos metodológicos. Portanto, esse evento se consolida como um polo de debates teóricos no universo da educação ambiental e resulta produtiva a análise dos materiais nele apresentados.

A pesquisa por nós empreendida teve com questões:

- Os trabalhos apresentados nos EPEAs explicitam alguma compreensão de uma dimensão política da educação ambiental?

- Quais concepções de educação ambiental estão presentes nos trabalhos dos EPEAs?

- Qual a abordagem política dessas concepções de educação ambiental?

Os objetivos a que nos propusemos foi a investigação do entendimento dado à dimensão política da educação ambiental nos trabalhos dos EPEAS, a caracterização das concepções de educação ambiental presentes nesses trabalhos e a identificação das abordagens políticas dessas concepções de EA.

\subsection{Procedimentos metodológicos}

A pesquisa que resultou neste artigo se caracteriza como uma análise documental (PIMENTEL, 2001) de abordagem qualitativa, pois a educação ambiental e sua dimensão política são fenômenos complexos e dinâmicos e procedimentos metodológicos apenas quantificáveis poderiam simplificar a análise pretendida (LUDKE; ANDRÉ, 1986).

Os trabalhos analisados foram escolhidos através de uma amostragem representativa aleatória, estratificada a partir das edições do EPEA, já que se considera que toda educação ambiental possui uma dimensão política e que, portanto, qualquer trabalho traria elementos para a análise a ser realizada, desde que contivesse elementos de uma determinada perspectiva de educação ambiental. A opção de aleatoriedade garantiria maior representatividade dos trabalhos, sendo possível constar no corpus documental inclusive os temas e instituições pouco representados, além de essa estratificação contemplar a representatividade segundo as edições dos eventos. Cabe destacar que essa opção envolveu uma discussão coletiva no Grupo de Pesquisa "A Temática Ambiental e o Processo Educativo"3 e a consulta a um professor de Estatística ${ }^{4}$ com experiência em trabalhos de pesquisa na área da educação.

Sob a orientação do professor de Estatística, decidiu-se por analisar 30\% (trinta por cento) dos trabalhos de cada evento de forma a garantir ao mesmo

3 Grupo de Pesquisa registrado no $\mathrm{CNPq}$ e do qual participam docentes e alunos da linha de pesquisa Educação Ambiental do Programa de Pós-Graduação em Educação $-\mathrm{IB} /$ Unesp/RC.

4 Prof. Dr. Antônio Carlos Simões Pião (DEMAC - Unesp/ Rio Claro). 
tempo certa representatividade dos trabalhos e uma quantidade possível de ser analisada.

O processo de organização desses materiais de forma a torná-los inteligíveis aos objetivos de nossa pesquisa, transformando-os em dados (LUNA, 2003), se deu da seguinte maneira: foram realizadas leituras exaustivas dos trabalhos buscando-se a formação de categorias, ou seja, das "rubricas ou classes, que reúnem um grupo de elementos [...] sob um título genérico, agrupamento esse efectuado em razão dos caracteres comuns" (BARDIN, 2004, p. 111). Essas categorias foram formadas tendo-se como referência as questões de pesquisa.

Conforme apontado por Bardin (2004), tratou-se de um momento que buscava dar ordem e sentido, com base em certos critérios, ao material aparentemente confuso presente nos trabalhos analisados. Procurou-se compreender as presenças ou ausências que faziam sentido às questões da pesquisa. Assim, as leituras buscavam destacar o que era mais apresentado, ou menos, nos trabalhos no tocante à compreensão da crise ambiental, seus determinantes e as possíveis soluções, perspectivas sobre educação, entre outras ideias que possibilitassem compreender qual a concepção de educação ambiental dos trabalhos na ótica da dimensão política, com o intuito de caracterizar as abordagens políticas de educação ambiental desses trabalhos.

Utilizamos como unidade de registro ${ }^{5}$ o tema, caracterizado como "unidade de significação que se liberta naturalmente de um texto analisado segundo certos critérios relativos à teoria que serve de guia à leitura". Trata-se de buscar descobrir "núcleos de sentido" que representem algo significativo para o objetivo da pesquisa (BARDIN, 2004, p. 99). A utilização do tema como unidade de registro não remete a recortes com critérios de forma, ou seja, não recorta palavras, frases ou parágrafos, refere-se a recortes semânticos, que podem remeter a um conjunto de palavras, frases ou parágrafos.

$\mathrm{Na}$ pesquisa que resultou neste artigo foi utilizado o trabalho integral como unidade de contexto ${ }^{6}$, ou seja, as análises foram realizadas a partir da significação que os temas (unidades de registro) adquiriam no contexto do conjunto dos trabalhos.

Através das leituras realizadas procedeu-se à diferenciação e ao reagrupamento dos trabalhos analisados. Inicialmente, foram construidos quadros com base nas ideias que os trabalhos traziam sobre a relação sociedadenatureza e também sobre educação, compreendendo-se que a educação ambiental envolve essas duas dimensões. Desmembraram-se, assim, os trabalhos nesses dois quadros enquanto se teciam observações sobre o trabalho de modo geral, na perspectiva da unidade de contexto.

5 Unidade de registro é "a unidade de significação a codificar e corresponde ao segmento de conteúdo a considerar como unidade de base, visando a categorização e a contagem frequencial" (BARDIN, 2004, p. 98).

6 "A unidade de contexto serve de compreensão para codificar a unidade de registro e corresponde ao segmento da mensagem, cujas dimensões [...] são óptimas para que se possa compreender a significação exacta da unidade de registro" (BARDIN, 2004, p. 100-101). 
Ao final da constituição desses quadros, constatou-se que ainda não seria possível compreender de forma mais detalhada as concepções de educação ambiental dos trabalhos, pois os dados brutos não haviam sido trabalhados suficientemente para proporcionar uma "representação simplificada" dos mesmos (BARDIN, 2004). Elaboraram-se então outros quadros, nos quais os trabalhos foram desmembrados a partir das suas características. Exemplos dessas características foram os trabalhos que faziam referência à participação política ou à educação numa perspectiva de emancipação, ou ainda a um retrato do sistema capitalista como uma das causas da degradação ambiental. Esse momento resultou em uma grande variedade de quadros e foram criados códigos para representar cada característica dos trabalhos. Por exemplo, o código 04 significava que o trabalho abordava a participação política. A partir desse inventário, desse processo de isolamento dos elementos (BARDIN, 2004), foi possível perceber detalhadamente quais eram as características mais presentes nos trabalhos e compreender melhor suas concepções.

O processo seguinte constitui-se na elaboração de resumos detalhados dos trabalhos para que se identificassem as ideias centrais dos textos e a concepção de cada um e se trabalhasse com a unidade de contexto. Esses resumos possibilitaram também a percepção das ideias que apareciam como acessórios nos trabalhos analisados e que, portanto, não representavam as concepções de educação ambiental desses trabalhos.

$\mathrm{Na}$ busca de encontrar "“núcleos de sentidos' que [...] pode[riam] significar alguma coisa para o objectivo analítico escolhido" (BARDIN, 2004, p. 99), definiram-se as seguintes categorias: concepção emancipatória de educação; concepção transformadora da relação sociedade-natureza (ambas sintetizando uma concepção transformadora de educação ambiental); concepção conservadora de educação e concepção conservadora da relação sociedadenatureza (ambas definindo uma concepção conservadora de educação ambiental). Tais categorias são representativas das concepções de educação ambiental dos trabalhos dos EPEAs considerando-se a dimensão política dessas concepções. As categorias foram constituídas através dos dados encontrados nos trabalhos e dos referenciais adotados.

Um dos referenciais usados é Campos (2000). Utilizando-se de duas categorias como ponto de partida das análises, a educação e a relação homemnatureza, Campos (2000) afirma que estas permitem problematizar a educação ambiental em suas dimensões pedagógica e epistemológica, considerando-as "sínteses de múltiplas determinações" a serem "desvendadas" na pesquisa. Foi em torno das ideias de educação e da relação sociedade-natureza presentes nos trabalhos dos EPEAs que as categorias foram desenvolvidas.

$\mathrm{O}$ significado dado a essas categorias se refere às possibilidades que as concepções apresentam de transformar a ordem social vigente e sua relação com a natureza ou conservar a "atual estrutura social, com todas as suas características e valores econômicos, políticos, éticos e culturais” (LIMA, 2005, p. 128). Tratase de observar as concepções de educação ambiental e sua dimensão política e questionar se essas concepções se apresentam para socializar o educando, 
"integrando-o aos valores culturais instituídos pelos grupos dominantes no poder”, ou para estabelecer perspectivas críticas da realidade histórica, propondo uma "alteração das injustas relações de poder" (LAYRARGUES, 2003a, p. 60).

Essas categorias respondem de maneira bastante nítida às questões da pesquisa. Ressalta-se, porém, que não se trata de uma perspectiva que considera binariamente as concepções de educação ambiental, pois é de conhecimento que nenhuma concepção de educação ambiental é puramente transformadora ou conservadora.

\subsection{Caracterização do corpus documental}

Este tópico apresenta uma breve caracterização do material analisado no intuito de proporcionar ao leitor maior conhecimento sobre o corpus desta pesquisa.

Há representantes de todas as regiões, e o Sudeste e o Sul possuem representantes de todos os estados. A Figura 1 apresenta a distribuição dos trabalhos por região.

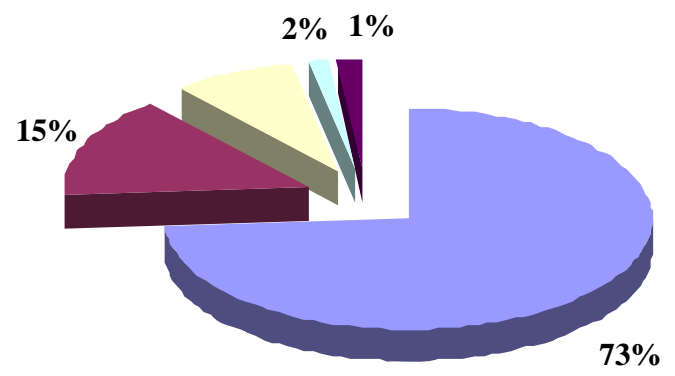

Sudeste

- Sul

Centro Oeste

Norte

Nordeste

Figura 1. Autorias dos trabalhos por região.

Ao observarmos somente as Instituições de Ensino Superior, que representam 92\% (119 autorias) das instituições em que foram produzidos os trabalhos, concluímos que há predomínio das universidades estaduais, seguidas pelas federais e particulares. A proporcionalidade está representada no gráfico que constitui a Figura 2. 


\section{Particulares \\ $22 \%$}

Federais

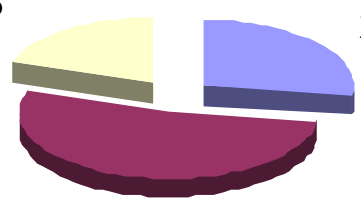

$27 \%$

\section{Estaduais \\ $53 \%$}

Figura 2. Autorias dos trabalhos por tipo de Instituição de Ensino Superior.

Pode-se observar a proporcionalidade dos temas na Figura 3.

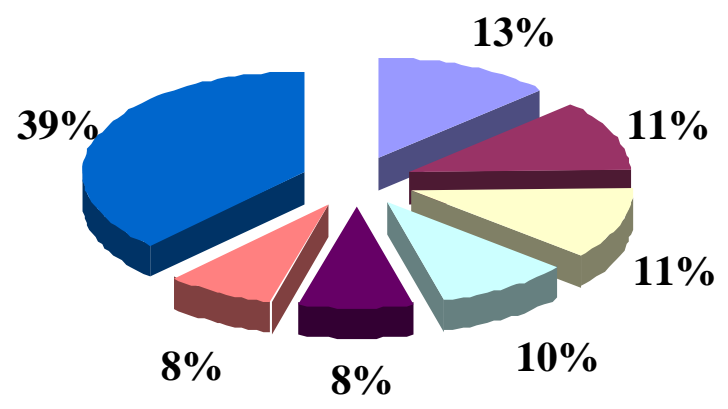

Concepção, percepção e

representação social

EA em comunidades

EA no contexto escolar

Formação de professores

- Fundamentos teóricometodológicos

Avaliação de programas/práticas de EA

Outros

Figura 3. Temas identificados nos trabalhos e sua frequência.

Os temas mais abordados são: "Concepção, percepção e representação social" (08), "EA em comunidades/coletivos urbanos, rurais, autóctones" (07), "EA no contexto escolar" (07), "Formação de professores" (06), "Fundamentos teórico-metodológicos da EA" (05) e "Avaliação de programas/práticas de EA" (05). Com base nesses dados, conclui-se que a maior parte dos trabalhos aborda temas referentes ao universo escolar (13), considerando-se nesse conjunto os trabalhos que debateram a formação de professores e a educação ambiental na escola.

Pode-se observar que há nos trabalhos analisados grande diversidade, referente às regiões de onde seus autores provêm, às suas instituições e aos temas abordados. Entretanto, é igualmente perceptível o predomínio de trabalhos da região Sudeste, das Instituições de Ensino Superior e, entre estas, das 
universidades públicas, além de maior incidência de trabalhos que remetem ao universo escolar.

\section{Concepções de educação ambiental e sua dimensão política}

A pesquisa que originou o presente artigo revelou certas características das abordagens políticas presentes nas concepções de educação ambiental dos trabalhos dos EPEAs, bem como a presença e o entendimento da dimensão política da educação ambiental. Diante da complexidade dos trabalhos analisados e do recorte estabelecido na pesquisa, é necessário que se considere a impossibilidade de apreensão total da realidade dos trabalhos; ao contrário, tratase aqui de apresentar certas características apreendidas na análise de concepções de educação ambiental presentes neles. Neste tópico são apresentadas reflexões a partir de uma visão de conjunto das concepções de educação ambiental analisadas.

Pode-se observar que a maior parte dos trabalhos apresenta matizes de uma concepção de educação ambiental considerada transformadora, indicando caminhos para a transformação da realidade socioambiental insustentável. Dos 61 (sessenta e um) trabalhos analisados, 39 (trinta e nove) situam-se mais próximos dessa perspectiva transformadora, o que representa $64 \%$ dos trabalhos.

As principais características que emergem dos trabalhos são referentes a processos educativos que promovem a emancipação, entendida aqui como a consciência do indivíduo sobre seu processo de autoconstrução, bem como sobre o processo histórico (TONET, 2005). Para tanto os trabalhos apresentam processos educativos que constroem, de modo cooperativo e crítico, conhecimentos sobre a realidade do educando. As relações de poder nos processos de formação humana, que impõem perspectivas culturais dominantes, bem como a ocultação desses processos, são também consideradas como alvos do questionamento dessa educação emancipatória presente no material analisado.

Exemplo de algumas dessas características é o excerto do Tr47, III EPEA, que apresenta como objetivo a análise das "sobreposições de idéias, estratégias e métodos entre o trabalho de Paulo Freire e o campo da educação ambiental". A autora discorre sobre o entendimento de homem e de educação em Paulo Freire afirmando que o autor compreende a educação como processo de conscientização, o que possibilita ao homem tornar-se sujeito de sua própria história:

Para ele, o homem pode ser visto através de duas dimensões, a dimensão natural e a dimensão cultural. A primeira engloba os aspectos mais biológicos e a segunda diz respeito àqueles aspectos de natureza criadora.

Assim, o ser humano é um agente interferidor da realidade, um sujeito criador de cultura, construtor de seus modos de vida. A produção de cultura é a forma de expressão e ação do homem sobre a natureza e sobre a realidade. Dessa forma, a alfabetização não pode ser vista apenas como a aquisição de técnicas de leitura e 
escrita, mas sim, como aquisição da capacidade de ler o mundo. A partir de um processo complexo de alfabetização há então a construção de uma proposta pedagógica mais ampla que visa à formação geral para a inserção e participação na esfera social. E, portanto, a educação é compreendida por Paulo Freire como um processo de conscientização. Tal conscientização possibilita ao homem se tornar o sujeito de sua própria história (Freire, 1982) (Tr47, III EPEA, p. 05-06).

Nos trabalhos, a aproximação com a realidade se dá no local de vivência dos educandos. Isso realmente permite uma compreensão concreta do mundo, por envolver o ambiente de vida, além de dar margem à intervenção transformadora, exigida pelas concepções presentes nesses trabalhos.

Compreende-se que a apreensão de problemas no macroespaço, no espaço global, é tida como abstrata, podendo desmobilizar uma possível atuação do educando. Apesar da necessidade do debate local/global, micro/macro, também assinalada pelos trabalhos, a intervenção na realidade para as comunidades, de modo efetivo, se dá no cotidiano (LAYRARGUES, 2003a). Deve-se estabelecer uma relação local-global-local.

A educação emancipatória pautada pelos trabalhos indica ainda que o sujeito pode participar ativamente da gestão de recursos naturais ou da solução coletiva de problemáticas ambientais.

O Tr64, III EPEA, "apresenta resultados da pesquisa realizada sobre a formação dos pedagogos na cidade de Curitiba para a prática da educação ambiental na educação infantil e no ensino fundamental". As autoras fazem referências à necessidade de vínculo do educando com sua realidade visando mostrar a necessidade de transformação dessa realidade:

Entre os pressupostos da educação ambiental expressos pela UNESCO (1976) estão o vínculo do educando com a realidade vivida pela comunidade de que faz parte e o desenvolvimento de valores que o motive[m] a perceber a necessidade de transformação dessa realidade, quer ela envolva problemas ambientais ou sociais. Dessa forma, a educação ambiental é um instrumento importantíssimo para a necessária mudança de valores da modernidade, tais como a justiça social e sustentabilidade socioambiental, tendo a participação como seu princípio básico. Deve, assim, ser um processo participativo através do qual o indivíduo e a coletividade constroem valores sociais, adquirem conhecimentos, tomam atitudes, exercem habilidades voltadas para a conquista da qualidade de vida e ambiental no espaço habitado, num contexto de justiça social (Tr64, III EPEA, p. 11-12).

Nos trabalhos, a emancipação considera o outro como sujeito de sua ação educativa e, ao caracterizar o papel do educador no sentido da mediação, compreende uma relação entre sujeitos, e não uma relação de submissão entre os polos sujeito-objeto. Nesse sentido, considera os saberes do educando, 
possibilitando a este a autonomia, já que compreende que a comunidade pode se valer de seus conhecimentos para reconstruir outros mais críticos sobre a realidade.

Os trabalhos delineiam um conhecimento concreto e histórico sobre a problemática ambiental, definindo quais são os sujeitos e os processos ocorridos na degradação ambiental, além de veicularem uma compreensão complexa da questão ambiental. $\mathrm{Na}$ maior parte dos trabalhos analisados, há referência a diversas dimensões da questão ou à necessidade de uma perspectiva ampla, complexa.

No Tr09, I EPEA, o objetivo é a análise de livros infantis como instrumentalização para a educação ambiental. As autoras procuram investigar se são abordadas nos livros questões como a participação política, valores, compreensão ampla da questão ambiental, entre outras. Caracterizam a problemática ambiental como multifacetada, afirmando a necessidade de transcender o âmbito das ciências físicas e biológicas. Segundo as autoras:

Sariego (1995) discute que a questão ambiental é também uma questão social, por envolver a coletividade humana; uma questão política porque para solucioná-la depende-se de uma posição e de uma vontade políticas, ultrapassando a ação individual, e exigindo-se a ação do poder público; uma questão econômica dado que o modo de produção e as formas de utilização dos recursos naturais expressam o grau de impacto da ação humana e por fim, uma questão psicológica, uma vez que a intensidade da motivação e envolvimento pessoais culminam na forma de relacionamento e conduta diante do meio ambiente (Tr09, I EPEA, p. 02).

Ao observarmos as características destacadas nos trabalhos, torna-se evidente certa gradação na perspectiva transformadora. Alguns trabalhos destacam uma perspectiva ampla da questão ambiental, relacionando diversos conhecimentos ou dimensões da realidade, mas não abordam, por exemplo, questões como os conflitos no âmbito da questão ambiental e o sistema capitalista como causador da degradação ambiental, capazes de aprofundar em radicalidade a perspectiva transformadora. Desse modo, é possível perceber que a relação entre transformação e conservação ambiental não se pauta por binarismo e que, apesar de, no limite, as concepções e práticas de educação ambiental estarem contribuindo mais para a conservação ou transformação, não há uma concepção de educação ambiental "pura".

O Tr27, II EPEA, aborda essa relação de conflito analisando a alfabetização ecológica proposta por Capra. O autor do trabalho considera que a alfabetização ecológica pretende solucionar a "aberração da natureza competitiva e conflituosa do humano" e afirma que:

É bom frisar que qualificar o caráter conflituoso da sociedade como uma aberração, que merece ser corrigida pelas leis da natureza, anula a existência da lógica do conflito nas formações sociais humanas, 
sobretudo nas periféricas do sistema capitalista. Essa perspectiva resulta na alienação das condições sociais que determinam a desigualdade na estrutura social, baseada em mecanismos de opressão social e política e exploração econômica. A concepção de Capra a respeito das formações sociais que deveriam ser harmoniosas, mas equivocadamente são conflituosas, corresponde a uma violência simbólica da ideologia hegemônica, a qual procura dissimular o conflito para camuflar a existência de diferentes grupos sociais na "luta pela sobrevivência" para utilizar a expressão darwiniana, pois o conflito é inerente ao humano. Quintas e Gualda (1995) lembram que "a sociedade não é lugar da harmonia, mas sobretudo, o lugar dos conflitos e confrontos que ocorrem em suas diferentes esferas (da política, da economia, das relações sociais, de valores, etc.)". Para Bobbio (1992), "um conflito social e político pode ser suprimido, isto é, bloqueado em sua expressão pela força, coercitivamente, como é o caso de muitos sistemas autoritários e totalitários. A supressão é, contudo, relativamente rara. Assim como, relativamente, é a plena resolução dos conflitos, isto é, a eliminação das causas, das tensões, dos contrastes que originaram os conflitos (quase por definição, um conflito social não pode ser 'resolvido')". Ainda para Quintas e Gualda (1995), como os conflitos são insolúveis, enfrentá-los exige a formulação conjunta de regras aceitas pelos atores sociais envolvidos na disputa, que estabeleçam limites ao conflito, regulamentando-os e institucionalizando-os (Tr27, II EPEA, p. 10).

A abordagem dos conflitos e da insustentabilidade capitalista coloca a questão ambiental entre as relações de poder e das diferenças ou divergências entre sujeitos, grupos, classes sociais, desnudando a ideia do homem genérico como "poluidor". O entendimento dos interesses e atores diversos, do uso diferenciado dos recursos naturais, bem como de projetos diferentes da relação sociedade-natureza, explicita a necessidade de tomada de posição e, nesse sentido, permite uma caracterização crítica, apurada da realidade. Concretiza-se, portanto, o entendimento de que se trata de uma relação amigo-inimigo na apropriação de recursos naturais, e não de uma sociedade cooperativamente buscando uma relação sustentável.

A gradação da radicalidade transformadora da realidade socioambiental se define nas concepções de EA a partir da medida em que se limita a compreensão dos conflitos na questão ambiental. A compreensão dos conflitos significa a compreensão de que a questão ambiental pertence à esfera política e de que a educação ambiental possui dimensão política.

É importante observar que, apesar do predomínio de uma concepção transformadora de educação ambiental, 22 dos 61 trabalhos analisados (36\%) foram caracterizados nas duas categorias referentes a uma concepção conservadora de educação ambiental.

É possível estabelecer relações entre as concepções de educação e de relação sociedade-natureza na abordagem conservadora. $O$ que perpassa essas 
concepções nos trabalhos é uma perspectiva a-histórica, que desconsidera efetivamente as relações sociais e busca adaptar os sujeitos a uma possível harmonização com a natureza ou ensinar comportamentos ambientalmente corretos. Nesse sentido, é possível buscar em Campos (2000) subsídios para reflexões sobre esses dados.

Campos (2000) trabalha, em sua tese, com as tendências natural, racional e histórica de educação ambiental. Interessa-nos aqui caracterizar a tendência natural e a racional, que compreendem a questão ambiental de modo a-histórico, pressupondo um homem "puro". A tendência natural apreende o homem como mais uma espécie, que estabelece relação direta com a natureza, sem mediações; desse ponto de vista, caberia à educação ambiental proporcionar um retorno do homem a uma relação harmônica com a natureza. A tendência racional compreende o homem como o ser "de razão", propondo a transmissão de conhecimentos a este para uma melhor relação com a natureza. Ambas compreendem uma adaptação do homem à sociedade, já que não possuem como foco o debate das relações sociais; a educação seria, portanto, uma educação do indivíduo, adaptadora, e não um processo coletivo.

As concepções conservadoras dos trabalhos analisados apresentam como característica central a compreensão de um homem genérico, responsabilizado pela crise ambiental, sem que se apreendam as relações históricas e sociais que determinam, em sociedades diversas, responsabilidades de diferentes sujeitos em relação à crise.

É possível observar fortemente essa concepção no Tr18, III EPEA, que analisa representações sociais sobre degradação ambiental de alunos do município de Jequié - BA. As autoras, ao debaterem seus dados, afirmam que os alunos possuem um entendimento correto das causas da degradação ambiental, pois percebem "que os maiores problemas ambientais em nossa sociedade são de origem antrópica". Ao analisarem as repostas dos alunos sobre a quem estes remetem a responsabilidade de proteção ambiental, afirmam que a maioria dos alunos atribui a responsabilidade a todos, mas que alguns a atribuem ao governo ou aos que agrediram o meio. As autoras criticam essas perspectivas afirmando que fazer parte do meio "obriga" todo ser humano a protegê-lo. Por fim, elas parecem fazer referência a uma perspectiva sistêmica, considerando o homem como parte de um encadeamento natural que não pode ser quebrado:

Os resultados indicaram que a maioria dos alunos, 83,9\% atribui essa tarefa a todas as pessoas, se incluíram como responsáveis, no entanto, um grupo de alunos ainda atribui esta responsabilidade a outros como governos e àqueles que provocaram a agressão. Mas fato é que todos são responsáveis pelos desastres cotidianos: a poluição das águas e do ar, os lixões, a venda de animais silvestres, isso faz parte do dia-a-dia, ainda assim, pouco se faz para coibir esses crimes (ALVES, MARANGONI, MOREIRA, 2004), além disso, fazer parte do meio ambiente, viver nele e precisar dele para sobreviver, é o suficiente para atribuir a obrigação a todo ser 
humano pela proteção e cuidado com o meio ambiente, de modo a torná-lo sustentável.

Desta forma, quer seja no ambiente escolar, familiar ou no trabalho, como professor, aluno, pai de família, profissional, cada um faz parte de um todo: o meio ambiente, cuja proteção é dever de todos. Portanto, é preciso lembrar uma das mais relevantes características da Terra: a íntima interdependência das partes que formam o conjunto. Tudo está ligado, formando um encadeamento que, desrespeitado, vai implicar a quebra de um ciclo natural (ALVES, MARANGONI, MOREIRA, 2004) (Tr18, III EPEA, p. 07).

Entende-se que dessa perspectiva depreende-se uma compreensão de que é o indivíduo que se relaciona imediatamente com a natureza, sem quaisquer mediações sociais, econômicas, culturais. A ideia de um homem genérico nos trabalhos se efetiva na compreensão do homem simplesmente como parte da natureza, ou mesmo de uma perspectiva que considera como principal causa da degradação ambiental o antropocentrismo.

A ideia do homem genérico acaba por delimitar processos de parcerias e cooperação entre os indivíduos da "espécie", ignorando os processos conflitivos e divergentes no âmbito social. Na perspectiva conservadora abordada pelos trabalhos, cabe à educação conscientizar os indivíduos levando conhecimento a eles e promovendo a mudança de seus comportamentos em relação à natureza; ou, de outro lado, a educação deve evocar uma sensibilização do sujeito para com o natural para que ele "retome" perspectivas de relacionamento mais harmônicas.

É possível observar o enfoque na mudança de comportamentos no Tr10, I EPEA, por exemplo, cujo objetivo foi analisar como um livro paradidático intitulado "Energia e meio ambiente" (BRANCO, 1990) poderia contribuir para a formação de alunos do $1^{\circ}$ ano do Ensino Médio. Ao analisar seus dados, a autora afirma que se utilizou de três categorias: "compreensão das noções básicas de energia", "conscientização da problemática ambiental" e "influência da leitura em relação às atitudes". Cita exemplos de alunos que, a seu ver, demonstram reflexão e atitudes para a preservação da natureza. A postura por ela caracterizada é definida pela preocupação com determinados comportamentos, tais como não pisar na grama e não desperdiçar energia:

$\mathrm{Na}$ redação, o sujeito criou um diálogo entre um homem e a D Sabedoria, em que demonstrou reflexão, relacionando energia e meio ambiente. Na seguinte declaração, o homem perguntou à $\mathrm{D}$. Sabedoria:

- Mas, e o meio ambiente? É impossível traçar um paralelo entre ele e a energia. Certo?

- Errado. Mas esta é a atitude da maioria das pessoas quando falamos neste assunto. $\mathrm{Na}$ verdade, ambos estão intimamente ligados, pois o meio ambiente é vida e vida é energia. 
A demonstração de atitudes, no sentido de contribuir para a preservação da natureza, se deu por meio do seguinte diálogo entre o homem e a D. Sabedoria:

- Entendeu a relação entre energia e meio ambiente?

- Entendi, e acho que a partir de hoje eu não vou pisar na grama, colher as flores, cortar árvores, desperdiçar energia... (Tr10, I EPEA, p.10).

A sensibilização e a mudança de comportamentos trabalham como adaptadores desses indivíduos a uma relação mais "harmônica" com a natureza dentro de um mesmo tipo de sociedade, já que as relações sociais não são o foco de sua ação. Aos moldes de uma educação adestradora, conforme enunciado por Brügger (1994), trata-se de ensinar um comportamento correto em relação à natureza: seja através de determinados sentimentos a serem estabelecidos, seja através de certas atitudes, não há o intuito de promover processos reflexivos e por meio destes construir valores e perspectivas mais transformadoras da realidade.

$\mathrm{Na}$ maioria dos trabalhos não se explicita uma adequada compreensão da relação entre educação e política e da dimensão política da educação ambiental. Da mesma forma, não compreendem a impossibilidade de neutralidade na educação e obscurecem o entendimento da esfera política como esfera social permeada de conflitos, de relações conservadoras ou transformadoras. Isso decorre do fato de que os trabalhos relacionam a educação ambiental à dimensão política somente no momento em que há o intuito declarado (e nem sempre sustentado) de uma educação transformadora, revolucionária. O Tr65, I EPEA, é exemplo dessa compreensão, este teve como objetivo fazer o levantamento da biodiversidade existente em uma comunidade de Mato Grosso. Com base em Guimarães (1995), os autores afirmam que a EA é um campo em construção e que não há modelos prontos, mas ideias a serem reelaboradas. Prosseguem afirmando que a educação ambiental exige postura crítica, que requer uma identidade política e que o adjetivo ambiental confere à EA um "status político":

A EA requer uma posição crítica, e um conhecimento produzido a partir da realidade vivenciada, e objetiva o equilíbrio local e global, para que haja uma melhoria na qualidade de vida. De acordo com GONÇALVEZ (1990 apud GUIMARÃES, 1995), "a EA não deve ser entendida como um tipo especial. Trata-se de um processo longo e contínuo de aprendizagem, de uma filosofia de trabalho participativo em que todos, família, escola e comunidade, devem estar envolvidos." Uma das formas de agir em relação [a] tudo [o] que vem ocorrendo em nosso meio ambiente, é realizando oficinas ecológicas. Sato (2001), entretanto, acredita que a EA seja diferente, nascida no bojo do movimento contracultural da década de 60, requer uma identidade política, embasada pelas lutas sociais e pelo movimento ambientalista que oportunizaram uma subversão de pensamentos e uma nova identidade aos/às educador@s ambientais, em especial à América Latina. Assim, o ambiente, tradicionalmente percebido como "adjetivo" da educação, 
confere um status político de significação diferenciada, tornando a EA como um verdadeiro substantivo composto de emancipação e lutas na construção de uma sociedade mais justa, com menos desigualdades sociais e com mais equilíbrio ecológico ( $\operatorname{Tr} 65$, I EPEA, p. 03-04, grifos do original).

Afirmar que o adjetivo ambiente confere status político à EA provoca confusão sobre sua não neutralidade. Da maneira como o texto é construído, passa-se o entendimento de que a educação ambiental deve ser preenchida de uma dimensão política, identificada com uma postura de lutas sociais etc., o que dificulta a compreensão de que a EA já possui uma dimensão política e de que esta pode ser inclusive contrária às lutas sociais.

\section{Considerações finais}

Os trabalhos considerados conservadores apresentam, em sua maior parte, referências a ideias consideradas transformadoras. Cavalari, Santana e Carvalho (2006) constatam nos trabalhos do I EPEA um predomínio da relação com uma tendência pedagógica crítica. Afirmam, entretanto, que poucos são os trabalhos que explicitam ou definem essa opção e que há pouca sistematização sobre os autores referenciados, que incluem Paulo Freire e José Carlos Libâneo.

A utilização de ideias transformadoras por abordagens de educação ambiental conservadoras traz certas reflexões importantes para a superação das confusões de referenciais políticos estabelecidas por esse quadro. Os trabalhos conservadores demonstram desse modo o intuito transformador que não se consegue cumprir por falta de fundamentação teórica, de reflexões mais críticas sobre a questão? Ou subentendem um conservadorismo dinâmico (LIMA, 2005), que pretende transformar, mas nos limites deste sistema? Há diferentes perspectivas sobre o que seriam processos de transformação social? Há uma tensão entre as perspectivas transformadoras e conservadoras, entre a ruptura social e a integração social? O que leva os autores dos trabalhos a não assumirem perspectivas definidas em nenhum sentido?

Sem a pretensão de respostas definitivas, considera-se, a partir dos dados analisados, que as propostas de transformação de realidade são diversificadas, o que pode ser observado entre as próprias categorias que abordam uma concepção de educação ambiental transformadora. Desse modo, o que aqui é considerado conservador pode perfeitamente ser considerado uma perspectiva transformadora segundo outros referenciais. Considera-se também que a realidade vem se apresentando de modo inexorável, o que vem inibindo propostas radicalmente transformadoras desta (FREIRE, 2001). Além disso, a educação ambiental é uma prática social recente, o que pode acarretar a falta de fundamentação teórica e reflexiva.

Os questionamentos acima elencados demonstram a validade do debate sobre as concepções e práticas acerca da educação ambiental. É importante destacar também que educadores são sujeitos deste momento histórico, que 
assumem - ou não - perspectivas sustentáveis; simplesmente adotar a questão ambiental e "tornar-se" um educador ambiental não remete a uma prática transformadora, ou ao menos, "bem-intencionada" (BRÜGGER, 1994).

\section{Referências}

ANDRÉ, M. E. D. A.; LUDKE, M. Pesquisa em educação: abordagens qualitativas. São Paulo: EPU, 1986.

BARDIN, L. Análise de conteúdo. Lisboa: Edições 70, 2004.

BORNHEIM, G. A. Filosofia e política ecológica. Ver. Filosóf. Brás, Rio de Janeiro, v. 1, n. 2, p. $17-$ 24, dez. 1985.

BRÜGGER, P. Educação on adestramento ambiental? Florianópolis: Letras Contemporâneas, 1994. (Teses).

CAMPOS, M. M. F. Educação ambiental e paradigmas de interpretação da realidade: tendências reveladas. 2000. 389 f. Tese (Doutorado em Educação) - Faculdade de Educação, Universidade Estadual de Campinas, Campinas, 2000.

CARVALHO, I. C. de M. A invenção do sujeito ecológico: sentidos e trajetórias em Educação ambiental. 2001. 411 f. Tese (Doutorado em Educação) - Universidade Federal do Rio Grande do Sul, Porto Alegre, 2001.

CAVALARI, R.; SANTANA, L. C.; CARVALHO, L. M. de. Concepções de educação e educação ambiental nos trabalhos do I EPEA. In: Pesquisa em Educação Ambiental, v. 1, n. 1, p.141-173, jul./dez. 2006.

DEMO, P. Participação é conquista: noções de política social participativa. São Paulo: Cortez: Autores Associados, 1998.

FREIRE, P. Pedagogia da Autonomia: saberes necessários à prática educativa. São Paulo: Paz e Terra, 2001.

FOLADORI, G. El pensamiento ambientalista. Tópicos en Educación Ambiental, México, v. 2, n. 5, p. 21-38, ago. 2000.

LAYRARGUES, P. P. A natureza da ideologia e a ideologia da natureza: elementos para uma sociologia da educação ambiental. 2003a. 111 f. Tese (Doutorado em Sociologia) - Instituto de Filosofia e Ciências Humanas, Universidade Estadual de Campinas, Campinas, 2003a.

. Educação Ambiental e Mudança Social. Texto apresentado como parte do curso Um Panorama da Educação Ambiental no Brasil. In: REUNIÃO ANUAL DA ANPED, 26., 2003b, Poços de Caldas. Disponível em: <http://www.anped.org.br/reunioes/26/outrostextos/mc22philip pepomierlayrargues.doc $>$. Acesso em: 20 maio 2011.

LIBÂNEO, J. C. Pedagogia e pedagogos, para quê? São Paulo: Cortez, 1998.

LIMA, G. F. C. Formação e dinâmica do campo da educação ambiental no Brasil: emergência, identidades, desafios. 2005. 207 f. Tese (Doutorado em Ciências Sociais) - Instituto de Filosofia e Ciências Sociais, Universidade de Campinas, Campinas, 2005.

LUNA, S. V. Planejamento de pesquisa: uma introdução. São Paulo: EDUC, 2002.

MARX, K. Para a crítica da economia política. Trad. José Carlos Bruni. 4. ed. São Paulo: Abril Cultural, 1987. 
PIMENTEL, A. O método da análise documental: seu uso numa pesquisa historiográfica. Cad. Pesq., São Paulo, n. 114, 2001. Disponível em: <http://www.scielo.br/>. Acesso em: 30 maio 2006.

SOFFIATI, A. Fundamentos filosóficos e históricos para o exercício da ecocidadania e ecoeducação. In: LAYRARGUES, P. P.; LOUREIRO, C. F. B.; CASTRO, R. S. (Org.). Educação Ambiental: repensando o espaço da cidadania. São Paulo: Cortez, 2002. p. 23-67.

TONET, I. Educar para cidadania ou para liberdade? Perspec., v. 23, n. 2, p. 469-484, 2005. Disponível em: <http:www.ced.ufsc.br>. Acesso em: 10 mar. 2007.

ZHOURI, A.; LASCHEFSKI, K.; PEREIRA, D. B. (Org.). A insustentável leveza da politica ambiental: desenvolvimento e conflitos socioambientais. Belo Horizonte: Autêntica, 2005.

Artigo recebido em 01/05/2011 e aprovado em 13/06/2011 